[2] L.J. Lu, et al., Lupus 19 (2) (2010)119-129.

[3] Isenberg DA, et al. Br J Rheumatol 1994;33:3078.

[4] Andrade RM, Arthritis Rheum (2007) 56(2):622-30

[5] Garcia MA, et al.. Lupus (2005) 14(12):938-46.

[6] Taraborelli M, et al. Lupus (2017) 11:1197-1204

[7] Tan TC, et al. J Rheumatol (2012) 39(4):759-69.

[8] Kamen DL, et al. Arthritis Rheum (2008) 58(5):1237-47

Disclosure of Interests: Micaela Fredi: None declared, Federica Tomasoni: None declared, Laura Andreoli: None declared, Ilaria Cavazzana: None declared, Angela Tincani Consultant for: UCB, Pfizer, Abbvie, BMS, Sanofi, Roche, GSK, AlphaSigma, Lillly, Jannsen, Cellgene, Novartis, Franco Franceschini: None declared

DOI: 10.1136/annrheumdis-2019-eular.2357

\section{FRI0236 MIGHT A 12-WEEK AEROBIC EXERCISE INTERVENTION IMPROVE PATIENT-REPORTED OUTCOMES IN WOMEN WITH SYSTEMIC LUPUS ERYTHEMATOSUS?}

Blanca Gavilán Carrera ${ }^{1}$, Jose Antonio Vargas-Hitos ${ }^{2}$, Pablo Morillas-de-Laguno ${ }^{1}$, Luis Manuel Saez-Uran², Antonio Rosales-Castillo' ${ }^{2}$, José Mario Sabioº, Raquel Ríos Fernández ${ }^{3}$, Alberto Soriano Maldonado ${ }^{4,5}$. ${ }^{1}$ Faculty of Sport Sciences, University of Granada, Department of Physical Education and Sport, Granada, Spain; ${ }^{2}$ Systemic Autoimmune Diseases Unit, "Virgen de las Nieves" University Hospital, Department of Internal Medicine, Granada, Spain; ${ }^{3}$ Systemic Autoimmune Diseases Unit, "San Cecilio" University Hospital, Department of Internal Medicine, Granada, Spain; ${ }^{4}$ SPORT Research Group (CTS-1024), CERNEP Research Center, University of Almería, Almería, Spain; ${ }^{5}$ Faculty of Education Sciences, University of Almería, Almería, Department of Education, Almería, Spain

Background: Despite the relevant advance in treatment options and survival rates in systemic lupus erythematosus (SLE), patient's quality of life (QOL) and other patient-reported outcomes (PROs) do not seem to improve accordingly [1]. PROs provide valuable information about the patient's perceptions across a variety of domains that should be considered in a successful management of this condition [2]. Exercise seems to be a safe way to improve cardiorespiratory fitness [3], and could have also a positive influence on PROs in SLE.

Objectives: To evaluate the effects of 12-week aerobic exercise intervention on PROs (QOL, depression, stress, and fatigue) in women with SLE. Methods: These are secondary outcomes of a non-randomized clinical trial [NCT03107442]. A total of 58 participants with SLE were assigned to exercise group $(n=26)$ or control group $(n=32)$. The exercise intervention followed the American College of Sports Medicine guidelines, and consisted of 12-week progressive aerobic exercise on a treadmill (2 sessions/week) between $40 \%-75 \%$ of the individual's heart rate reserve [3]. Attendance of $>75 \%$ was set for inclusion in the analyses. The control group received verbal information about a healthy lifestyle. At baseline, and at week 12, PROs were assessed including the physical and mental summary scores of the 36-item Short-Form Health Survey (SF-36), depression (Beck Depression Inventory; BDI-II), perceived stress (visual analogue scale) and fatigue (Multidimensional Fatigue Inventory; MFI-20). A total of 49 women with SLE (age: $44.5 \pm 14.2$ years) completed all the assessments (exercise $=21$; control=28) and were included in the per-protocol (primary) analyses. The exercise and control group were comparable in age, disease duration and SLE activity, sociodemographic characteristics, and BMI at baseline, although there were differences in BDI-II scores. Baseline values and BDI-II values were used as covariates in the analyses.

Results: In comparison to the control group, the exercise group showed a significant reduction in general fatigue (mean difference -2.11 units; $95 \% \mathrm{Cl}-4.18$ to $-0.04 ; P=0.046$ ) and physical fatigue (mean difference 3.90 units; $95 \% \mathrm{Cl}-6.3$ to $-1.5 ; P=0.002$ ) following the intervention. There were no between-group differences in the changes from baseline to week 12 either in physical $(P=0.828)$ or mental $(P=0.767)$ QOL, depression $(P=0.498)$, perceived stress $(P=0.247)$ or other fatigue dimensions (mental, reduced motivation, reduced activity, all $P>0.05$ ).

Conclusion: The results of this study suggest that 12 weeks of progressive aerobic exercise might improve relevant dimensions of fatigue in women with SLE, despite absence of effects on QOL, depression or perceived stress.
REFERENCES:

[1] Mcelhone K, Abbott J, Teh L-S. A review of health related quality of life in systemic lupus erythematosus. Lupus. 2006;15: 633-643.

[2] Mahieu M, Yount S, Ramsey-Goldman R. Patient-reported outcomes in systemic lupus erythematosus. Rheum Dis Clin. Elsevier; 2016;42: 253263.

[3] Soriano-maldonado A, Morillas-de-laguno P, Sabio M. Effects of 12-week Aerobic Exercise on Arterial Stiffness, Inflammation, and Cardiorespiratory Fitness in Women with Systemic LUPUS Erythematosus: Non-Randomized Controlled Trial. J Clin Med. 2018; 1-17.

Disclosure of Interests: None declared

DOI: 10.1136/annrheumdis-2019-eular.6789

\section{FRI0237 OMEGA-3 AND OMEGA-6 FATTY ACIDS IN SJÖGREN'S SYNDROME: CLINICAL IMPLICATIONS AND THEIR ASSOCIATION WITH INFLAMMATION}

Gabriela Hernandez-Molina, Carlos Castrejón-Morales, Omar Granados-Portillo, Ivette Cruz-Bautista, Narlly Ruiz-Quintero, lliana Manjarrez, Diego HernándezRamírez, Guadalupe Lima, Miguel Astudillo-Angel, Luis Llorente. Instituto Nacional de Ciencias Médicas y Nutrición Salvador Zubirán, Mexico City, Mexico

Background: Essential $\omega-3$ and $\omega-6$ fatty acids (FA) are natural modulators of inflammation activity; however, their role in primary Sjögren's syndrome (pSS) is unknown.

Objectives: To evaluate the intake and serum levels of $\omega-3$ and $\omega-6$ FA in patients with pSS, and to correlate them with ocular and oral signs and symptoms, disease activity as well as with the presence of a panel of inflammatory chemokines/cytokines in saliva and tears.

Methods: We included 108 patients with pSS according to EULAR/ACG criteria. We excluded patients under $\omega-3$ and $\omega-6$ supplementation. Dietary information was obtained from a semiquantitative food frequency questionnaire of one-day reminder (applied by a trained interviewer), and processed using computerized nutritional analysis software. Fasting blood samples were collected. We measured the serum levels of $\omega-3$ ( $\alpha$-linolenic acid $[\alpha-L]$, eicosapentaenoic acid [EPA], docosahexaenoic acid $[\mathrm{DHA}]$ ) and $\omega-6$ (linoleic acid [LA], arachidonic acid [AA]) using gas chromatography flame ionization. We assessed the ESSDAl score, ESPPRI, OSDI, tear film break-up time, Schirmer-I test and the SICCA Ocular Staining Score (OSS). In a subgroup of patients, we obtained tears and saliva samples that were frozen at $-86^{\circ} \mathrm{C}$ until assayed. Once defrosted, the levels of CXCL8, CXCL10, CCL2, IL-22 and IL-21 in saliva and CXCL8, CXCL10, CCL2 and CXCL9 in tears were measured by Luminometry.

Results: The median age was $56.12 \pm 13.7$ years, 94.4\% women and median disease duration 10 years. The FA $\omega-3$ and $\omega-6$ intake was 0.43 $\mathrm{g} /$ day and $3 \mathrm{~g} / \mathrm{d}$, respectively. The levels of $\alpha-L$ were $6.6 \mu \mathrm{g} / \mathrm{mL}$, DHA $26 \mu \mathrm{g} / \mathrm{mL}$, total $\omega-3(\alpha-\mathrm{L}+\mathrm{DHA}) 25.4 \mu \mathrm{g} / \mathrm{mL}$, LA $168.5 \mu \mathrm{g} / \mathrm{mL}$, AA 34 $\mu \mathrm{g} / \mathrm{mL}$, and total $\omega-6(\mathrm{LA}+\mathrm{AA}) 205 \mu \mathrm{g} / \mathrm{mL}$. We did not find a correlation among serum levels and food intake. Thus, further analyses were focused on serum results. We found a negative correlation between $\alpha$-L and the OSDI $(\rho=-0.42, \quad \mathrm{p}=0.01)$ and $\operatorname{ESSDAI}(\rho=-0.26, \quad \mathrm{p}=0.03)$ as well of DHA and ESSDAI $(\rho=-0.30, p=0.01)$. The rest of the variables were not associated. In tears, there was a positive correlation of AA and CXCL9 $(\rho=0.48, p=0.04)$, whereas in saliva, we observed a negative correlation between $\alpha-L$, DHA and total $\omega 3(\alpha-L+D H A)$ with CCL2. We also observed a negative correlation between total $\omega 6(\mathrm{LA}+\mathrm{AA})$ and IL21 , and the $\omega 6 / \omega 3$ ratio with IL-22.

Conclusion: Our pSS patients had deficient FA omega intake. We observed lower ocular symptoms, lower ESSDAI scores and salivary levels of CCL2 among patients with higher levels of FA $\omega-3$. Our study suggest that low serum levels of $\omega-3$ might be implicated in the perpetuation of chronic inflammation.

Disclosure of Interests: None declared

DOI: 10.1136/annrheumdis-2019-eular.5646 